\title{
Evaluation of factors controlling large earthquake-induced landslides by the Wenchuan earthquake
}

\author{
X. L. Chen ${ }^{1}$, H. L. $\operatorname{Ran}^{1}$, and W. T. Yang ${ }^{2}$ \\ ${ }^{1}$ State Key Lab of Active Tectonics and Volcano, Institute of Geology, China Earthquake Administration, \\ Beijing, 100029, China \\ ${ }^{2}$ Academy of Disaster Reduction and Emergency Management, Beijing Normal University, Beijing, 100875, China
}

Correspondence to: X. L. Chen (04chxl@sina.com)

Received: 4 June 2012 - Revised: 5 November 2012 - Accepted: 5 November 2012 - Published: 12 December 2012

\begin{abstract}
During the 12 May 2008, Wenchuan earthquake in China, more than 15000 landslides were triggered by the earthquake. Among these landslides, there were 112 large landslides generated with a plane area greater than $50000 \mathrm{~m}^{2}$. These large landslides were markedly distributed closely along the surface rupture zone in a narrow belt and were mainly located on the hanging wall side. More than $85 \%$ of the large landslides are presented within the range of $10 \mathrm{~km}$ from the rupture. Statistical analysis shows that more than $50 \%$ of large landslides occurred in the hard rock and second-hard rock, like migmatized metamorphic rock and carbonate rock, which crop out in the south part of the damaged area with higher elevation and steeper landform in comparison with the northeast part of the damaged area. All large landslides occurred in the region with seismic intensity $\geq X$ except a few of landslides in the Qingchuan region with seismic intensity IX. Spatially, the large landslides can be centred into four segments, namely the Yingxiu, the Gaochuan, the Beichuan and the Qingchuan segments, from southwest to northeast along the surface rupture. This is in good accordance with coseismic displacements. With the change of fault type from reverse-dominated slip to dextral slip from southwest to northeast, the largest distance between the triggered large landslides and the rupture decreases from $15 \mathrm{~km}$ to $5 \mathrm{~km}$. The critical acceleration $a_{\mathrm{c}}$ for four typical large landslides in these four different segments were estimated by the Newmark model in this paper. Our results demonstrate that, given the same strength values and slope angles, the characteristics of slope mass are important for slope stability and deeper landslides are less stable than shallower landslides. Comprehensive analysis reveals that the large catastrophic landslides could be specifically tied to a particular
\end{abstract}

geological setting where fault type and geometry change abruptly. This feature may dominate the occurrence of large landslides. The results will be useful for improving reliable assessments of earthquake-induced landslide susceptibility, especially for large landslides which may result in serious damages.

\section{Introduction}

Landslides and collapses triggered by strong earthquakes have drawn more and more attention due to the serious damages they caused. For example, the vast majority of the more than 1000 victims of the El Salvador earthquakes of 13 January $\left(M_{\mathrm{w}}=7.7\right)$ and 13 February $2001\left(M_{\mathrm{w}}=6.7\right)$ were directly caused by landslides (Bommer et al., 2002). Also, during the Wenchuan earthquake in China in 2008, about 20000 deaths were directly caused by the geohazards in the form of landslides, rockfalls, and debris flows (Yin et al., 2009).

The important factors that affect landslides distribution during a strong earthquake are in general rock mass type, landform, slope degree, seismic intensity, earthquake magnitude and distance from the seismic faults or epicenter, etc. Many studies about earthquake-induced landslides have been drawn on the relationship between landslide distribution and the influencing factors mentioned above (Harp et al., 1981; Harp and Jibson, 1996; Guzzetti et al., 1999; Rodríguez et al., 1999; Keefer, 1984, 2000). Keefer (1984) compiled 40 examples of earthquake triggered landslides from all over the world and studied their characteristics (Keefer, 1984). His findings about the relationship between landslides and 
seismic parameters have been quoted widely (Wilson and Keefer, 1985; Rodríguez et al., 1999; Bommer et al., 2002; Qi et al., 2010; Chen et al., 2012). Except the analysis research done on a number of earthquake examples, additional work has been carried out on the landslides characteristics and distribution features during a single earthquake event, such as the 1994 Northbridge earthquake in US, the 1999 Chi-chi earthquake in Taiwan, and especially the 2008 Wenchuan earthquake in China (Qiao and $\mathrm{Pu}, 1992$; Rodríguez et al., 1999; Jibson et al., 2000; Wang et al., 2003; Wang et al., 2007; Wang et al., 2008; Huang et al., 2008; Chen et al., 2010). Almost all the results show similar understandings of the relationship between influencing factors and landslides distribution, but there are some new findings in the recent event of the Wenhchuan Earthquake in China, 2008.

The Wenchuan earthquake occurred at the middle segment of the Longmenshan thrust belt at the eastern margin of the Tibetan Plateau, which is characterised by rugged topography, steep high mountains, deep valleys and complicated geological structure. Historically, this region is famous for its various kinds of geohazards (Qiao and Pu, 1992; Yang et al., 2002). After the Wenchuan earthquake, post-seismic field investigations as well as the interpretation of space images and aerial photographs have revealed more than 15000 geohazard sites in the damaged area (Yin, 2009). Besides triggering thousands of landslides during this event, there are also lots of landslides with great volumes exceeding several ten million cubic meters, which often cause fatalities. For example, the Donghekou rock avalanche, which occurred in Qingchuan with an estimated volume of $2.3 \times 10^{8} \mathrm{~m}^{3}$, buried one primary school and 184 houses, resulting in more than 780 deaths (Yuan et al., 2010).

Compared with ordinary scale landslides, landslides with a large scale of volume or plane area like deep-seated landslides and rock avalanches can cause more serious damage (Yin et al., 2009). Remote sensing interpretation showed that during the Wenchuan earthquake there were a total of 112 large landslides generated, each of which had a plane area greater than $50000 \mathrm{~m}^{2}$, blending of source area and deposition area, and can be classified as a deep-seated landslide or rock avalanche (Xu and Li, 2010; Qi et al., 2011). Among them were many large landslides with a volume bigger than ten millions cubic meters (Huang et al., 2008; $\mathrm{Xu}$ and $\mathrm{Li}$, 2010). The fact that so many large landslides with different types of failure mechanisms and sliding dynamics occurred simultaneously in a single triggering event is out of expectation, thus scientists are anxious to search for the answers.

Due to such amount of large landslides in the Wenchuan earthquake triggered by a single event, it is appropriate to consider large landslides as a special kind of landslide. Although large scale landslides show some distribution rules similar to the ordinary landslides, they also present some unique features in their distribution as well as sliding mechanisms and dynamics, Hsü's (1975) detailed studied sturzstroms mechanism and kinematics, as well as the relationship between the rock avalanches travel distance and their volumes. He proposed that the sturzstroms could be compared to flow of a mass of concentrated cohesionless grains in a fluid medium, and found that the coefficient of friction was different when rock fall sizes changed: it decreased above a threshold landslide size of about $100000 \mathrm{~m}^{3}$ (Hsü, 1975). Studies about the large landslide mechanisms and characteristics are presented after the Wenchuan earthquake (Sassa et al., 2005; Yin, 2009; Huang et al., 2010; Wu et al., 2010; Qi et al., 2011). Some researchers consider that air cushion effect is important to long run out avalanches (Yin, 2009; Wu et al., 2010). Also, it has been found that most of the long run out rock avalanches have source areas with high relief and steep inclination, and that the saturated Holocene loose deposits could be the most important factor causing the long run out rock avalanches (Qi et al., 2011).

Apart from the general factors composed of landslides context setting, the effects of seismic fault mechanism and geometry on landslides development has not been studied in depth. Although some earthquake-induced landslides examples showed that thrust fault can cause more landslides in a wider region and result in landslides prone to occur on the hanging wall side rather than the foot side, such as the 1999 Chi-Chi earthquake in Taiwan, the 2004 Niigata earthquake in Japan and the 1994 Northridge earthquake in US as well as the 2008 Wenchuan earthquake in China (Harp and Jibson, 1996; Jibson et al., 2000; Wang et al., 2003; Kieffer et al., 2006; Wang et al., 2007; Huang et al., 2008; Yin et al., 2009; Chen et al., 2010; Dai et al., 2011), thorough investigations are still scarce. Such amounts of large landslides occurring in a single event provide a good opportunity for this study.

In this paper, considering large landslides as a special kind of landslides, after analysis of the interplay between the geological setting and the distribution of large landslide development, the influence of fault type and geometry is discussed and preliminary estimation of the critical acceleration $a_{\mathrm{c}}$ for four typical large landslides is calculated. Then a comprehensive discussion of the possible causes of the large landslides is given.

\section{Interplay between tectonics and distribution of large landslides}

The $2008 M_{\mathrm{s}}=8.0$ Wenchuan earthquake occurred at the Longmenshan fault zone (LSFZ) at the eastern margin of the Tibetan Plateau, an area that is deforming as a result of the collision between the Indian plate and the Eurasian plate. The NE-NNE trending LSFZ, which is about $500 \mathrm{~km}$ long and $30 \sim 50 \mathrm{~km}$ wide, mainly consists of three sub-parallel thrust faults, namely the Wenchuan-Maowen (F1), YingxiuBeichuan (F2), and Guanxian-Jiangyou (F3) faults (Fig. 1). Late Archean to Cenozoic rocks and Quaternary sediments crop out in the region (Fig. 1). A simplified strata system is given in Table 1. 
Table 1. Simplified geologic strata system of the area most severely damaged by the $M_{\mathrm{S}}=8.0$ Wenchuan earthquake (revised after Qi et al., 2011).

\begin{tabular}{lll}
\hline Sequence & Symbol & Lithology \\
\hline Holocene & Qh & Alluvium \\
Pleistocene & Qp & Loose deposit \\
Cretaceous & K & Conglomerate \\
Jurassic & J & Sandy slate, mudstone, sandy stone intercalated with mudstone \\
Triassic & T & Sandy stone, limestone, slate \\
Permian & P & Thick limestone intercalated slate \\
Carboniferous & C & Limestone, marble and sandy stone \\
Carboniferous-Devonian & C-D & Carbonate rock, sandy conglomerate \\
Devonian & D & Quartzose sandstone \\
Silurian & S & Sandy stone, phyllite intercalated with limestone \\
Ordovician & O & Limestone, marble and phyllite of Baota formation \\
Cambrian & $\epsilon$ & Metomorphic sandy conglomerate, limestone \\
Sinian & Z & Metamorphic sandy stone, metamorphic limestone \\
Archean & Pt & Granite, diorite, gabbro \\
\hline
\end{tabular}

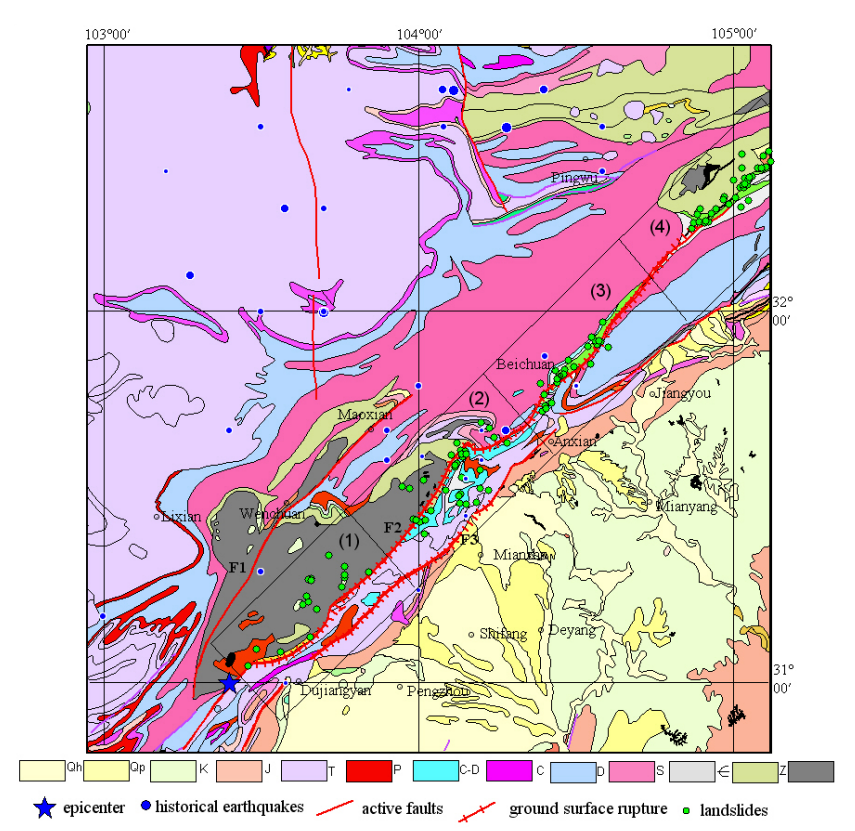

Fig. 1. Geology map of the Wenchuan earthquake and the distribution of large landslides. F1: Wenchuan-Maowen fault, F2: YingxiuBeichuan fault, F3: Guanxian-Jiangyou fault. (1) Yingxiu segment; (2) Gaochuan segment; (3) Beichuan segment; (4) Qingchuan segment

The Wenchuan earthquake triggered thousands of landslides ranging in size from rock falls of a few cubic meters to rock avalanches of tens of millions cubic meters. A total of 112 large landslides (Fig. 1), each of which has a plane area larger than $50000 \mathrm{~m}^{2}$, have been detected by remote image interpretation among these landslides ( $\mathrm{Xu}$ and $\mathrm{Li}, 2010)$.

Spatially, landslides triggered by earthquake have a close relationship with causative seismic faults and they are

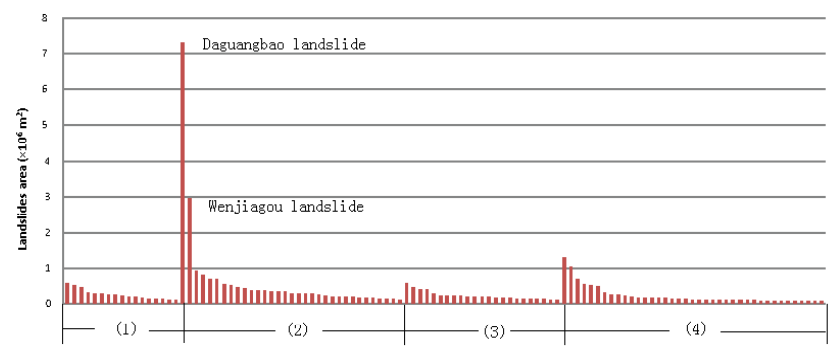

Fig. 2. Area of large landslides of different segments. (1) Yingxiu segment, (2) Gaochuan segment, (3) Beichuan segment and (4) Qingchuan segment.

clustered along the faults, as have been proved by many studies (Keefer, 1984, 2002; Khazai and Sitar, 2003; Wang et al., 2003; Wen et al., 2004; Wang et al., 2007; Qi et al., 2010; Dai et al., 2011). This is the case in the Wenchuan earthquake, as the large landslides are mainly dominated by the causative faults from the southwest to the northeast (Fig. 1). However, the spatial distribution of the large landslides appears unevenly along the seismic faults, with certain areas subject to many failures whereas other areas are essentially unaffected. From the epicenter at the southwest to the northeast, large landslides can be concentrated at four segments, namely the Yingxiu segment, the Gaochuan segment, the Beichuan segment and the Qingchuan segment (Fig. 1). The quantity and plane areas of the large landslides are different between the segments (Table 2). The Qingchuan segment has the largest amount (39) of large landslides, whereas the Gaochuan segment has the biggest landslides area (20 $\left.292454 \mathrm{~m}^{2}\right)$. However, the average landslide plane area of these segments is similar, except a few extra large landslides in the Gaochuan segment such as the Daguangbao landslide $\left(7.0 \times 10^{6} \mathrm{~m}^{2}\right)$ and the Wenjiagou landslide $\left(2.9 \times 10^{6} \mathrm{~m}^{2}\right)$ (Fig. 2). 
Table 2. Distribution of large landslides and their plane areas.

\begin{tabular}{lrrrr}
\hline Segment & Yingxiu & Gaochuan & Beichuan & Qingchuan \\
\hline Quantity & 17 & 33 & 23 & 39 \\
Total area $\left(\mathrm{m}^{2}\right)$ & 4093201 & 20292454 & 4746898 & 8193967 \\
Average area $\left(\mathrm{m}^{2}\right)$ & 240766 & 614922 & 206386 & 210101 \\
\hline
\end{tabular}

\subsection{Correlation between large landslides and seismic faults}

Landslides triggered by earthquakes have a closer relationship with tectonic settings than that triggered by other factors. Researches on earthquake-induced landslides show that causative faults influence the distribution of landslides during a strong shaking event (Khazai and Sitar, 2003; Wen et al., 2004; Wang et al., 2008) and, with the increasing of the distance from the causative fault or epicenter, the number of triggered landslides presents a negative-exponential decline (Simonett, 1967; Keefer, 2000; Wang et al., 2007).

Statistical analysis of the landslides in the Wenchuan earthquake indicates that the number of earthquake-induced landslides decreases with increasing distance to the seismic faults. Almost $80 \%$ of landslides are within $30 \mathrm{~km}$ to the seismic faults and are spread unevenly in the damaged region. More than $87 \%$ of landslides were located on the hanging wall side of the LSFZ where most of the large aftershocks ( $M \geq 4.0)$ occurred (Chen et al., 2010).

Unlike normal landslides, large landslides in the Wenchuan earthquake show distinctly close relationship with the causative seismic faults in spatial distribution. They are only limited to a very narrow zone from the ground surface rupture. All the 112 large landslides are within a $15 \mathrm{~km}$ buffer to the ground surface rupture. Among them, 44 large landslides occurred within a $1 \mathrm{~km}$ distance to the ground surface rupture and more than $80 \%$ of the large landslides are within $5 \mathrm{~km}$ distance (Xu et al., 2010). Meanwhile, when compared with other normal landslides, the number of large landslides drops more rapidly as the distance from the seismic faults increases, although they all have negative-exponential decline (Fig. 3).

\subsection{Correlation between large landslides and topography}

Beside the magnitude of the Wenchuan earthquake, the abrupt change of topography in the damaged area is another important factor predisposing to landsliding.

Topographically, the LSFZ is a transitional zone from the Tibetan Plateau to the Sichuan Basin plain. Its relief gradually decreases eastward (Fig. 4a). On the western side of the LSFZ, the elevation is commonly above $3000 \mathrm{~m}$, while on the east side of the LSFZ, especially in the Sichuan Basin, it is lower than $800 \mathrm{~m}$. The plateau margin has the

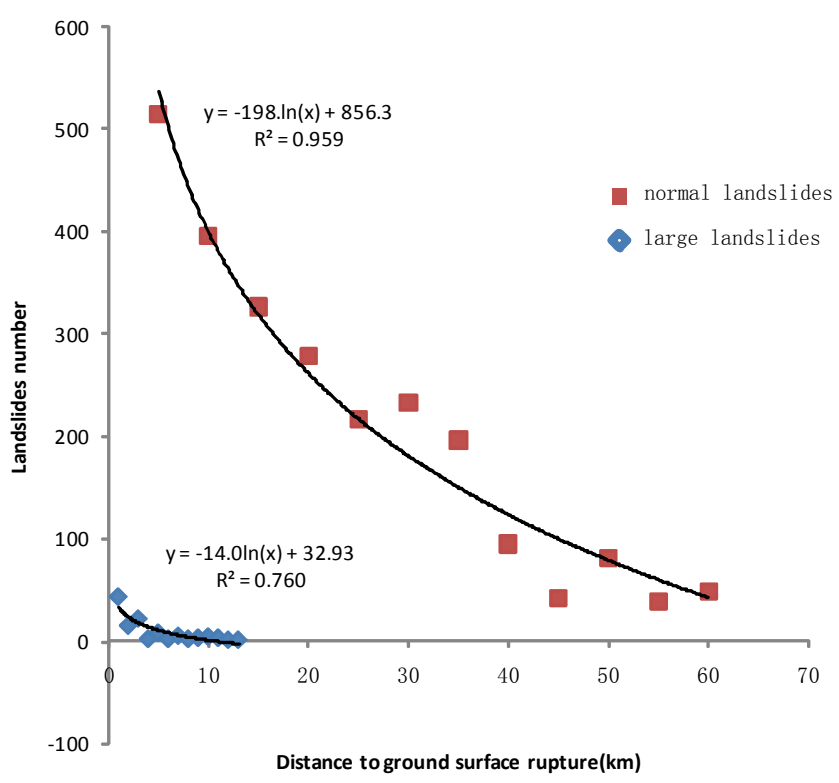

Fig. 3. Relationship between large landslides and distance from the ground surface rupture.

steepest topographic gradient among any existing plateau edge (Densmore et al., 2007).

Geologically, the large landslides are distributed strictly within the Longmenshan thrust fault belt, where relief changes sharply. On the whole, elevation at the southwest region is higher than at the northeast. From southwest to northeast, four profiles (section A, B, C, D) are drawn at the places where large landslides are concentrated. With respect to the Beichuan segment and the Qingchuan segment, topography is steeper at the Yingxiu segment and the Gaochuan segment (Fig. 4a and b).

Generally, almost all the large landslides occurred at steep slopes with the gradient of $\geq 20^{\circ}$. Meanwhile, more than $70 \%$ of the large landslides have an original slope degree of $\geq 30^{\circ}$ (Fig. 5a). In respect to ordinary landslides, large landslides are more likely to occur at steeper slopes. However, the area damaged by large landslides is not obviously affected by the degree of the slope (Fig. 5b). 

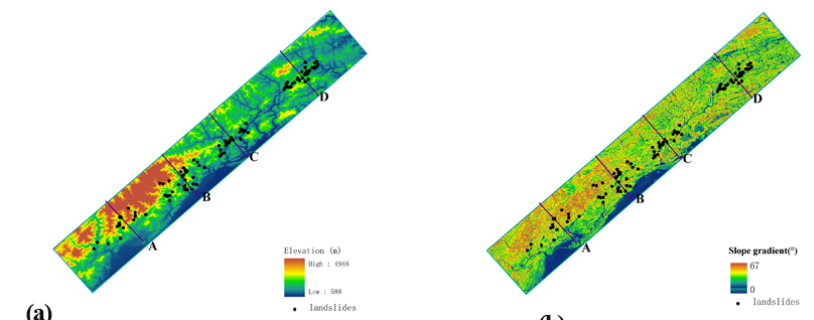

(a)
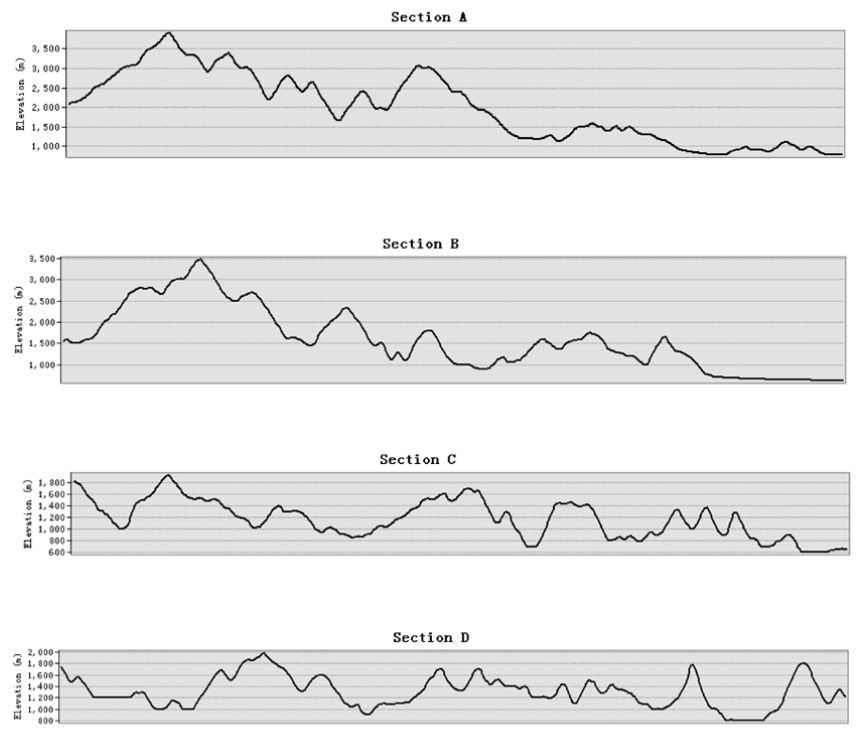

(c)

Fig. 4. Topography of study region. (a) Elevation; (b) Slope gradient; (c) 4 cross sections at A, B, C, D.

\subsection{Correlation between the large landslides and rock mass type}

Although it is generally known that landslides are likely to occur in weak rocks, in the area affected by the Wenchuan earthquake, slope failures can be frequently found in hard rocks like granite and limestone, just as in large landslides (Fig. 1).

The study area is dominated by the pre-Tertiary units. Tertiary and Quaternary sediments are limited to the southeast edge of the LSFZ, and are adjacent to Sichuan Basin (Fig. 1). According to rock engineering standards ("Standard for engineering classification of rock masses", GB50218-94, China, 1995), the study area can be mainly classified into four rock types: the hard rock group, second-hard rock group, the soft rock group and second-soft rock group (Fig. 6). Near the epicenter region, the strata are mainly composed of a set of migmatized metamorphic rock and migmatite, named the famous "Pengguan massif", which belongs to the hard rock type. Second-hard rock group in this area includes carbonate rock, i.e. limestone and conglomerate, while the soft rock group includes shale and other metamorphic rocks.
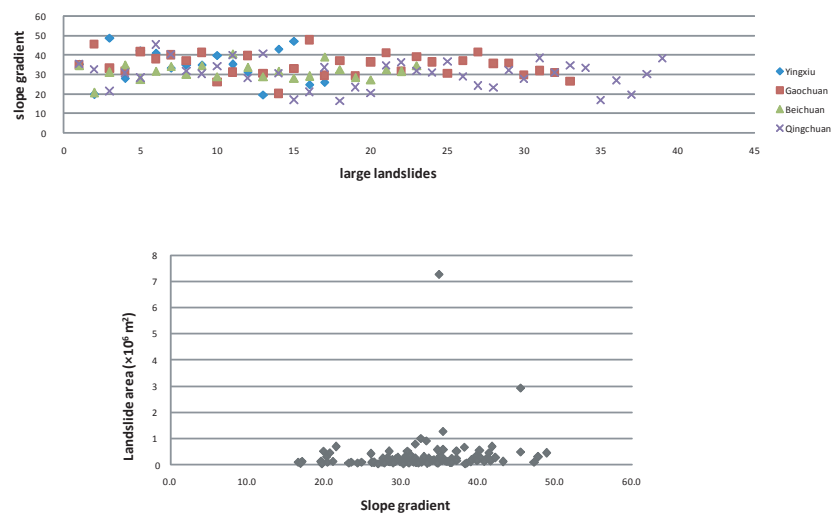

Fig. 5. Large landslides slope degrees at different segments (a) and the relationship between landslides areas and slope degrees (b).

Statistical analysis shows that there are 15, 44 and 53 large landslides that occurred in the hard rock group (type I), second-hard rock group (type II) and soft rock group (type III), respectively (Fig. 6b). From the epicenter to the northeast along the rupture direction, the rock property changes from the hard rock group (type I) to second-hard rock group (type II) and then to soft rock group (type III) (Fig. 6).

Taking account of seismic rupture propagation direction as well as elevation and landform changes, there exists an interesting combination of geological settings for large landslides. The harder the rock type, the steeper relief is needed for forming large landslides.

\subsection{Correlation between large landslides and coseismic displacements}

Field investigations indicated that the $M_{\mathrm{s}}=8.0$ Wenchuan earthquake generated a $240 \mathrm{~km}$ and a $90 \mathrm{~km}$ long surface ruptures along the Beichuan-Yingxiu fault (F2 in Fig. 1) and the Guanxian-Jiangyou fault (F3 in Fig. 1), respectively (Xu et al., 2009).

According to Yu et al. (2010) study, the coseismic displacements are not even along the surface rupture zone. Beichuan-Yingxiu grounds ruptures can be divided into 2 main segments: the Yingxiu segment at south part and the Beichuan segment at north part. These segments are separated by the Gaochuan jog. Deformation along these two segments is different: reverse faulting is dominant at the Yingxiu segment, while along the Beichiuan segment, a more $1: 1$ ratio between the right-lateral motion and the vertical motion exists (Yu et al., 2010).

Based on the investigation of the coseismic displacements along the surface ruptures (Yu et al., 2010), four bigger coseismic displacement centred zones can be delineated from southwest to northeast along the surface rupture, and they are the Yingxiu segment, the Gaochuan segment, the Beichuan segment and the Qingchuan segment (Figs. 7 and 8). Along 


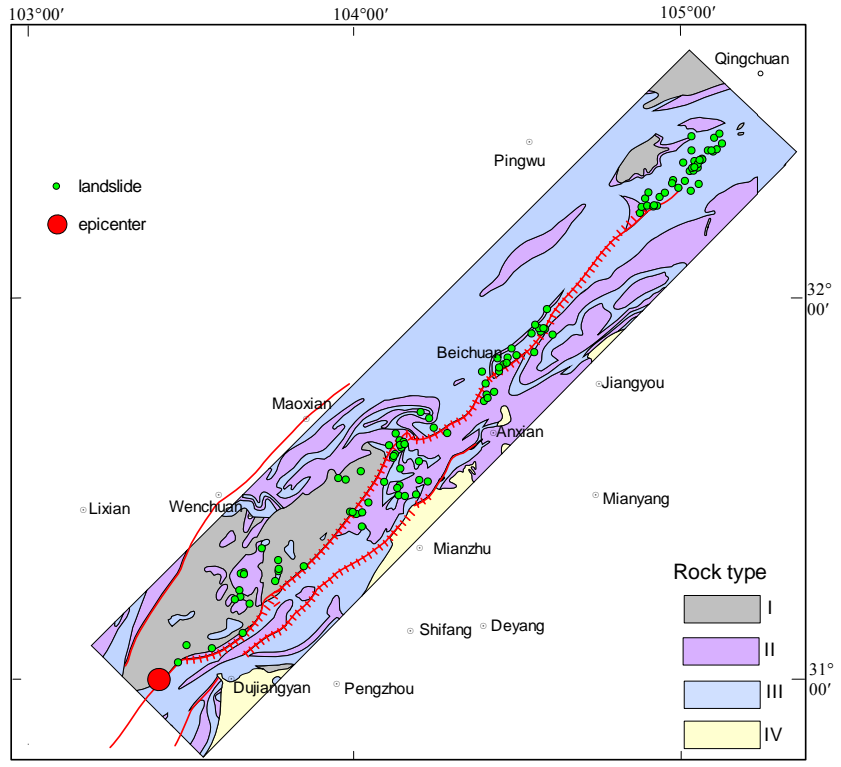

(a)

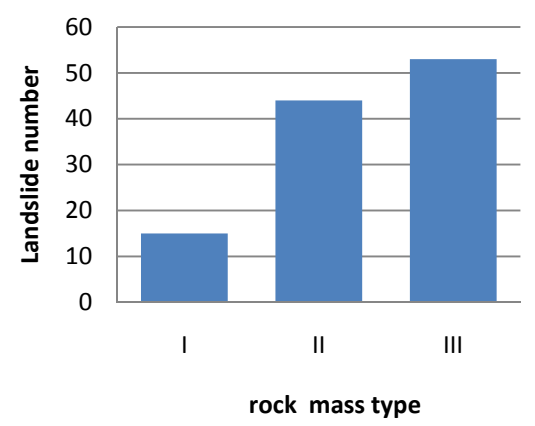

(b)

Fig. 6. Regional rock properties (a) and large landslides number distributed in different rock mass (b). I: hard rock group; II: secondhard rock group; III: soft rock group; IV second-soft rock group.

with the physical distribution of large landslides, it can be found that the concentration distribution of the coseismic displacements correlates with large landslides (Fig. 7).

$\mathrm{Yu}$ and her colleagues had measured horizontal and vertical coseismic displacements in the field (Yu et al., 2010). In this paper, total displacement $\left(D_{\mathrm{t}}\right)$ is used to describe the ground surface deformation, too. It is expressed as a combination vector value of horizontal and vertical coseismic displacement following the equation at a special observation position:

$\mathrm{D}_{\mathrm{t}}=\sqrt{\mathrm{D}_{\mathrm{h}}^{2}+\mathrm{D}_{\mathrm{v}}^{2}}$

where $D_{\mathrm{h}}$ is horizontal coseismic displacement $(\mathrm{cm})$ and $D_{\mathrm{v}}$ is vertical coseismic displacement $(\mathrm{cm})$.

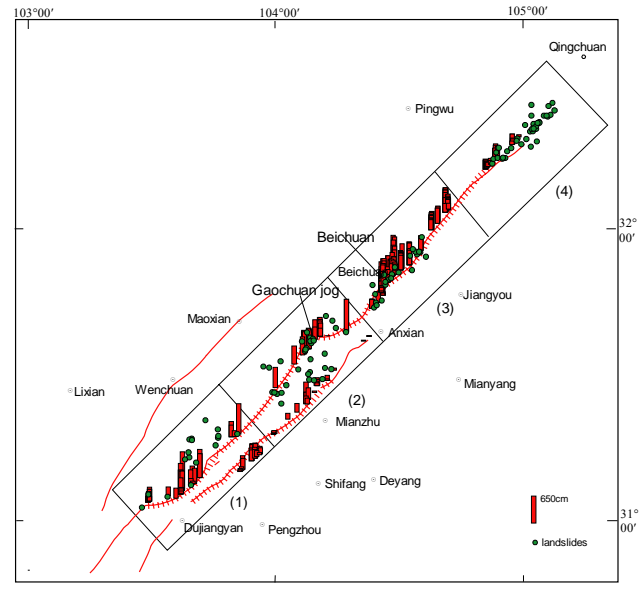

(a)

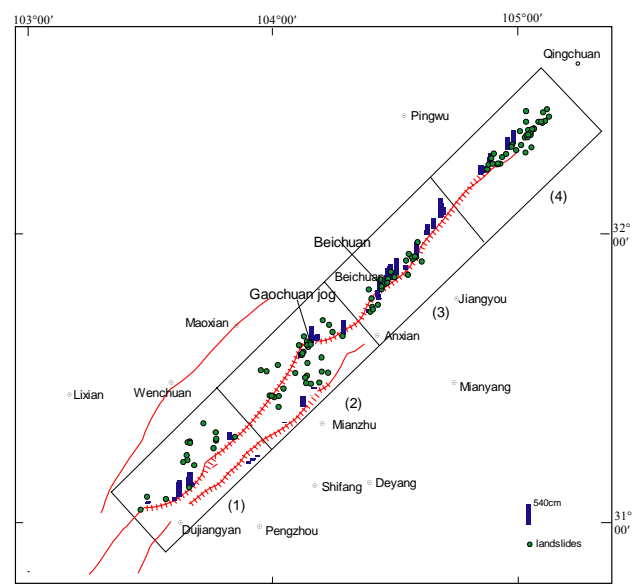

(b)

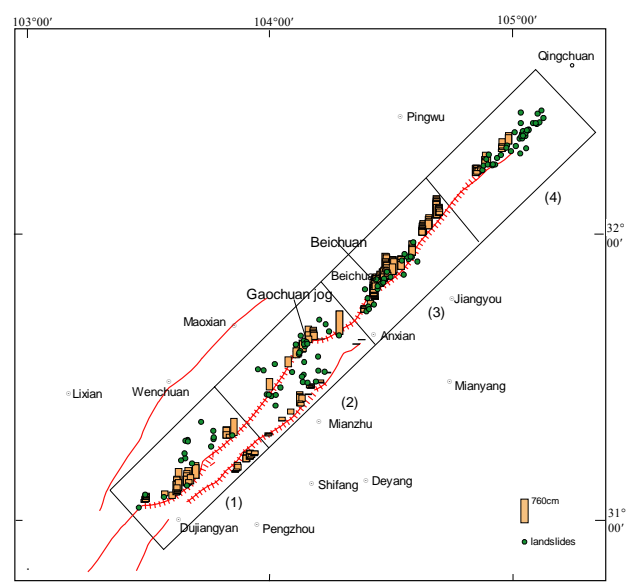

Fig. 7. Distribution of the coseismic displacements measured in the field (revised after Yu et al., 2010). (a: vertical coseismic displacements distribution; b: horizontal coseismic displacements distribution; $\mathbf{c}$ : total coseismic displacements distribution; (1) Yingxiu segment, (2) Gaochuan segment, (3) Beichuan segment and (4) Qingchuan segment). 


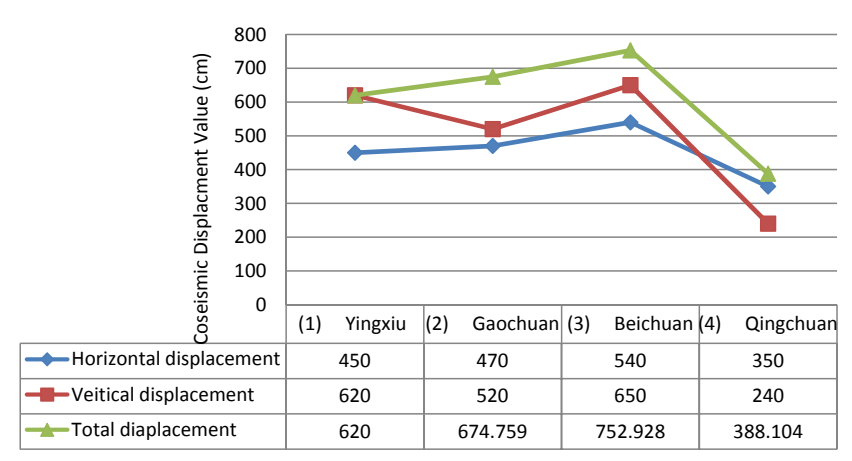

Fig. 8. Maximum coseismic displacements at different segments.

Table 3 shows the maximum coseismic displacement values of the four segments. Both the biggest vertical and horizontal displacements are presented at the Beichuan segment (Table 3, Fig. 8), they are measured $6.5 \mathrm{~m}$ and $5.4 \mathrm{~m}$, respectively (Yu et al., 2010).

For horizontal displacement, the value becomes bigger and bigger along the rupture propagation direction from the epicenter region to the northeast, until at the Qingchuan segment, then there is a drop. For vertical displacement, at the epicenter section and the Beichuan segment, the values are bigger than other segments, and the minimum value is presented at the Qingchuan segment. As to the total displacements, the maximum value appears at the Beichuan segment, that was one of the most damaged regions in the Wenchuan earthquake. It is notable that all the horizontal, vertical and total displacements decrease at the Qingchuan segment.

The variety of coseismic displacement values in different segments along the ground surface ruptures reveals the change of fault type and fault geometry (Haeussler et al., 2004; Shen et al., 2009; Yu et al., 2010). Overlaid with large landslides physical distribution, the concentration distribution of coseismic displacements is in good accordance with large landslides. This means that where the bigger coseismic offsets slipped, heavier slope failures occurred. Meanwhile, at the places where the fault type and fault geometry changed, the slope failures were heavier, such as at the transforming positions (like the Beichuan county in the Beichuan segment) and the faults junctions (like the Gaochuan segment).

\subsection{Distribution of large landslides with ground motion}

As the trigger of earthquake-induced landslides, seismic ground motion plays an important role in the occurrence of landslides. Research and reports indicate that the landslides distribution could be closely related to the distribution of peak ground acceleration (Harp el al., 1981; Keefer, 1984; Wang et al., 2003; Meunier et al., 2007; Wang et al., 2007). During the 1999 Chi-Chi earthquake in Taiwan, earthquakeinduced landslides rate generally increased with peak ground acceleration (PGA) increasing, and more than $90 \%$ of the

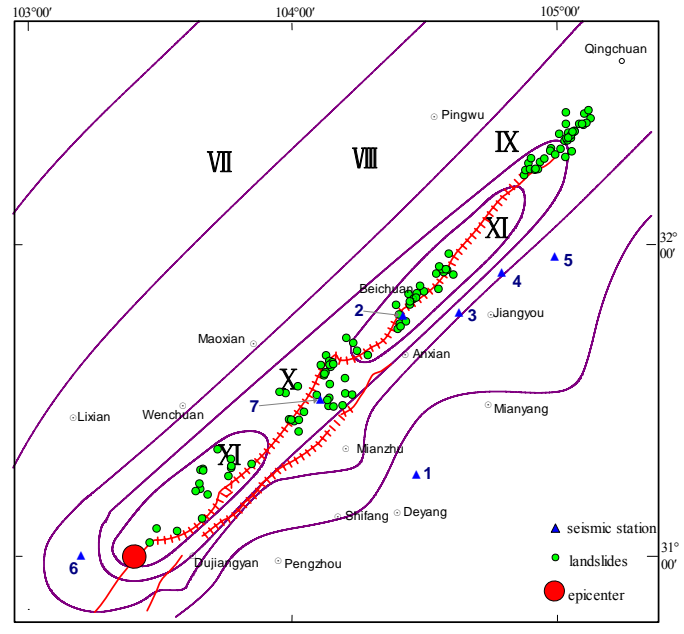

Fig. 9. Distribution of large landslides with seismic intensity.

landslides were distributed in the area where PGA exceeded $300 \mathrm{gal}$ in the horizontal component (Wang et al., 2003). In the Wenchuan earthquake, more than $70 \%$ of the landslides were presented in the area with PGA greater than 354 gal, this value corresponds to seismic intensity VIII when scaled in China seismic intensity (Li et al., 2008; Chen et al., 2010).

Lots of references indicate that the threshold intensity for triggering small landslides is of approximately seismic intensity VI (Harp et al., 1981; Keefer, 1984), as is also proved to be true in the Wenchuan earthquake (Chen et al., 2010; Qi et al., 2010). But as to large scale landslides triggered by the Wenchuan earthquake, it is found that almost all the large landslides occurred in the region of seismic intensity higher than X except several events that occurred in seismic intensity IX in the Qingchuan region, the northeast end of the surface rupture (Fig. 9). This fact reveals a closer tie between the large landslides and their geological locations. The zone where it is likely to form large scale landslides is much narrower than that for generating comparative small scale landslides, and strong ground motion is an important factor of determining large landslide incidence.

Although hundreds of seismic instrument records of main shock were obtained during the Wenchuan earthquake, near field seismic data is not optimal for further studying. Table 4 lists seven seismic ground motion records which were obtained at or around the area damaged by large landslides. Among them, No. 6, named Wolong Seismic Station, recorded the strongest ground motion. Peak accelerations recorded in the EW, NS, and vertical directions are 957.7, 652.9, and 948.1 gal, respectively ( $\mathrm{Li}$ et al., 2008). 
Table 3. Maximum coseismic displacements at different segments.

\begin{tabular}{lccc}
\hline $\begin{array}{l}\text { Segment } \\
\text { name }\end{array}$ & $\begin{array}{c}\text { Horizontal displacement } \\
(\mathrm{cm})\left(D_{\mathrm{h}}\right)\end{array}$ & $\begin{array}{c}\text { Vertical displacement } \\
(\mathrm{cm})\left(D_{\mathrm{v}}\right)\end{array}$ & $\begin{array}{c}\text { Total displacement }) \\
(\mathrm{cm})\left(D_{\mathrm{t}}\right)\end{array}$ \\
\hline $\begin{array}{l}\text { (1) Yingxiu } \\
\text { (2) Gaochuan }\end{array}$ & 450 & 620 & 620.0 \\
(3) Beichuan & 470 & 520 & 674.759 \\
(4) Qingchuan & 540 & 650 & 752.928 \\
\hline
\end{tabular}

Table 4. Peak accelerations recorded in the near stations.

\begin{tabular}{llllllll}
\hline $\begin{array}{l}\text { Seismic } \\
\text { station }\end{array}$ & $\begin{array}{l}\text { Lat. } \\
\left({ }^{\circ}\right)\end{array}$ & $\begin{array}{l}\text { Long. } \\
\left({ }^{\circ}\right)\end{array}$ & $\begin{array}{l}\text { Distance from } \\
\text { rupture }(\mathrm{km})\end{array}$ & $\begin{array}{l}\mathrm{E}-\mathrm{W} \\
(\mathrm{gal})\end{array}$ & $\begin{array}{l}\mathrm{N}-\mathrm{S} \\
(\mathrm{gal})\end{array}$ & $\begin{array}{l}\text { U-D } \\
(\mathrm{gal})\end{array}$ & $\begin{array}{l}\text { Total } \\
(\mathrm{gal})\end{array}$ \\
\hline 1 & 104.46 & 31.26 & 35.0 & 129.0 & 90.8 & 139.1 & 210.31 \\
2 & 104.41 & 31.77 & 1.6 & 493.4 & 548.6 & 214.4 & 768.54 \\
3 & 104.62 & 31.78 & 13.0 & 347.0 & 512.5 & 448.1 & 764.10 \\
4 & 104.78 & 31.91 & 17.0 & 470.2 & 519.6 & 210.8 & 731.78 \\
5 & 104.98 & 31.96 & 19.0 & 279.9 & 302.8 & 214.2 & 464.66 \\
6 & 103.2 & 31.0 & 19.2 & 957.7 & 652.9 & 948.1 & 1497.5 \\
7 & 104.1 & 31.5 & 2.3 & 824.1 & 802.7 & 622.9 & 1308.2 \\
\hline
\end{tabular}

* Locations of 7 seismic stations are shown in Fig. 9.

\section{Discussion}

\subsection{Influence of seismic fault mechanism and geometry on the triggered landslides}

As important influencing factors of landslides, the effects of seismic fault mechanism as well as fault geometry are not clear. Landslides triggered by $M_{\mathrm{s}}=8.0$ Wenchuan earthquake provide a good opportunity to explore this relationship.

Oglesby's study on the Chi-Chi earthquake indicated the effects of fault geometry, nonuniform prestress, and dynamic waves on the physics of the Chi-Chi earthquake and dip-slip faults (Oglesby and Day, 2001). Abrahamson and Somerville's study proposed that thrust and reverse faults can cause stronger ground motion in their hanging walls (Abrahamson and Somerville, 1996). Studies on the Wenchuan earthquake revealed faults spatially distribution features have controlling effects on the aftershocks occurrence, and at the same time, aftershocks relocation of the Wenchuan earthquake supported that most of the aftershocks occurred within the LSFZ and on the hanging walling sides (Zhu et al., 2008; Zhang et al., 2009; Zhao et al., 2010). The fact that landslides were likely to occur on the hanging wall side can be contributed to the abnormally high ground motions on it (Abrahamson and Somerville, 1996; Harp and Jibson, 1996; Jibson et al., 2004). It is apparently that during the Wenchuan earthquake, which was caused by thrust faults, hanging wall and footwall sides experienced different intensity of ground motion and consequent high concentrations of landslides on hanging wall, as appeared in other earthquakes caused by thrust faults, such as the 1999 Chi-Chi earthquake in Taiwan, the 2004 Niigata earthquake in Japan and the 1994 Northridge earthquake in US (Harp and Jibson, 1996; Wang et al., 2003; Jibson et al., 2004).

Analysis of Global Positioning System and Interferometric Synthetic Aperture Radar data about the Wenchuan earthquake indicates that the geometry of the fault changes along its length: in the southwest, the fault plane dips moderately to the northwest but becomes nearly vertical in the northeast (Shen et al., 2009). Besides, the motion along the fault changes from predominantly thrusting to strike-slip (Shen et al., 2009). Moreover, as to the landslides concentrated places such as Yingxiu town, Gaochuan town and Beichuan County, these regions are the intersections of fault segments where peak slip along the fault occurs (Shen et al., 2009). Integrating coseismic displacements with the occurrence of large landslides, it is found that with the change of fault type from reverse dominated to dextral from southwest to northeast, the maximum distance between large landslides and the ground surface rupture decrease (Fig. 10). This fact indicates that a reverse fault can trigger large landslides in a wider region (at southwest part) than a strike-slip fault does (at northeast part). Therefore, a primary study shows fault type and geometry may influence the landslides spatial distribution on the landslides location, size, density, and so on.

\subsection{Influences of peak ground motion on landslides}

Strong correlations were found between the variations of landslide density and both the vertical and horizontal components of recorded peak ground accelerations (Meunier et 
Table 5. Slopes composed of coherent rock material with thickness of $20 \mathrm{~m}$.

\begin{tabular}{lrrrrrrr}
\hline Landslide & $c^{\prime}(\mathrm{Mpa})$ & $\alpha\left(^{\circ}\right)$ & $\varphi^{\prime}\left(^{\circ}\right)$ & $t(\mathrm{~m})$ & $\lambda\left(\mathrm{kN} \mathrm{m}^{-3}\right)$ & Fs & $a_{\mathrm{c}}(\mathrm{gal})$ \\
\hline Niujuangou & 2.5 & 40 & 65 & 20 & 30.0 & 9.037 & 4871.0 \\
Daguangbao & 2.0 & 45 & 55 & 20 & 27.0 & 6.666 & 3776.0 \\
Wangjiayan & 1.0 & 37 & 45 & 20 & 25.0 & 4.650 & 2152.0 \\
Donghekou & 1.0 & 40 & 45 & 20 & 24.0 & 4.433 & 2162.0 \\
\hline
\end{tabular}

Table 6. Slopes composed of coherent rock material with thickness of $10 \mathrm{~m}$.

\begin{tabular}{lrrrrrrr}
\hline Landslide & $c^{\prime}(\mathrm{Mpa})$ & $\alpha\left(^{\circ}\right)$ & $\varphi^{\prime}\left({ }^{\circ}\right)$ & $t(\mathrm{~m})$ & $\lambda\left(\mathrm{kN} \mathrm{m}^{-3}\right)$ & Fs & $a_{\mathrm{c}}(\mathrm{gal})$ \\
\hline Niujuangou & 2.5 & 40 & 65 & 10 & 30.0 & 15.520 & 9146.7 \\
Daguangbao & 2.0 & 45 & 55 & 10 & 27.0 & 11.904 & 7556.0 \\
Wangjiayan & 1.0 & 37 & 45 & 10 & 25.0 & 7.973 & 4112.9 \\
Donghekou & 1.0 & 40 & 45 & 10 & 24.0 & 7.674 & 4204.1 \\
\hline
\end{tabular}

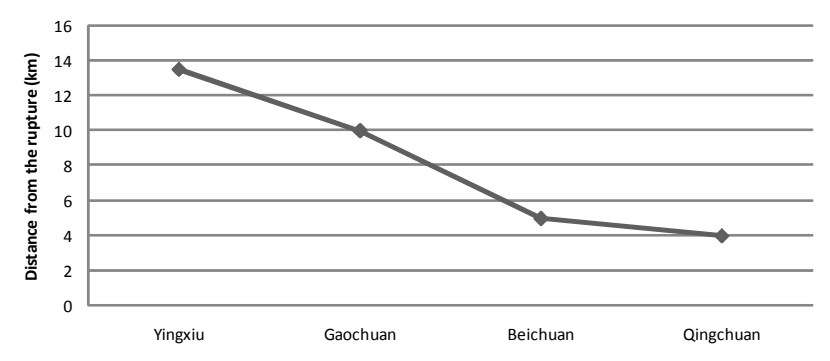

Fig. 10. Maximum distances of large landslides to the ground surface rupture at different segments.

al., 2007). Studies on the distribution characteristics of the Wenchuan earthquake induced landslide also support this viewpoint (Wang et al., 2003; Keefer et al., 2006; Wang et al., 2008; Qi et al., 2010; Chen et al., 2010).

After selecting four typical large landslides from the four large landslides concentrated segments separately, the authors tried to estimate critical acceleration $a_{\mathrm{c}}$ for generating the events based on the Newmark model and compare calculated $a_{\mathrm{c}}$ with the peak ground acceleration obtained by seismic instruments records. These four large landslides are the Niujuangou landslide in the Yingxiu segment, the Daguangbao landslide in the Gaochuan segment, the Wangjiayan landslide in the Beichuan segment and the Donghekou landslide in the Qingchuan segment (Fig. 11).

In the Newmark model (1965), it is shown that critical acceleration of a potential landslide block is a simple function of the static factor of safety and landslide geometry, expressed as

$a_{\mathrm{c}}=\left(F_{\mathrm{S}}-1\right) g \sin a$

where $a_{\mathrm{c}}$ is the critical acceleration in terms of $g$, the acceleration of Earth's gravity; $F_{\mathrm{S}}$ is the static factor of safety; and $\alpha$ is the angle from the horizontal that the centre of mass of the potential landslide block first moves, which can generally be approximated as the slope angle.

$F_{\mathrm{S}}$ is expressed as:

$F_{\mathrm{S}}=\frac{c^{\prime}}{\gamma t \sin \alpha}+\frac{\tan \varphi^{\prime}}{\tan \alpha}-\frac{m \gamma_{\mathrm{w}} \tan \varphi^{\prime}}{\gamma \tan \alpha}$

where $\varphi^{\prime}$ is the effective friction angle, $c^{\prime}$ is the effective cohesion, $\alpha$ is the slope angle, $\gamma$ is the material unit weight, $\gamma_{\mathrm{w}}$ is the unit weight of water, $t$ is the slope-normal thickness of the failure slab, and $m$ is the proportion of the slab thickness that is saturated. Because the season when the Wenchuan earthquake took place was not the wet season, superficial slope materials were dry. Therefore, no pore-water pressure is included $(m=0)$ in this calibration, and the third term drops from the equation.

Two situations of the slopes are calculated here, one is where slopes are composed of coherent rock material, and another is where slopes are composed of fractured rock material. Under different conditions, the parameters of rock materials are different. The varied parameters are effective friction angle $\varphi^{\prime}$ and effective cohesion $c^{\prime}$. Based on the landslides' material components and for simplicity, rock materials parameters are assigned as showing in Tables 5-8 according to "Standard for engineering classification of rock masses" (GB50218-94, China). Meanwhile, the slope angles for different landslides are taken from their practical typical slope angles, while the thickness is taken the same value of $10 \mathrm{~m}$ and $20 \mathrm{~m}$, respectively. After calculation, the results of critical acceleration $a_{\mathrm{c}}$ and static factor of safety $F_{\mathrm{S}}$ are also listed in Tables 5-8.

The Newnark model has been applied widely and successfully in seismic landslides hazard assessment (Jibson et al., 2000; Jibson and Michael, 2010; Scott and Keefer, 2001). Although our calculation about the four large landslides is based on the Newnark model with simplified parameters, some preliminary useful understanding is achieved 
Table 7. Slopes composed of fracture rock with thickness of $20 \mathrm{~m}$.

\begin{tabular}{lrrrrrrr}
\hline Landslide & $c^{\prime}(\mathrm{Mpa})$ & $\alpha\left(^{\circ}\right)$ & $\varphi^{\prime}\left({ }^{\circ}\right)$ & $t(\mathrm{~m})$ & $\lambda\left(\mathrm{kN} \mathrm{m}^{-3}\right)$ & Fs & $a_{\mathrm{c}}(\mathrm{gal})$ \\
\hline Niujuangou & 0.25 & 40 & 40 & 20 & 30.0 & 1.648 & 408.33 \\
Daguangbao & 0.22 & 45 & 35 & 20 & 27.0 & 1.2763 & 191.466 \\
Wangjiayan & 0.15 & 37 & 25 & 20 & 25.0 & 1.117 & 69.18 \\
Donghekou & 0.15 & 40 & 25 & 20 & 24.0 & 1.042 & 26.45 \\
\hline
\end{tabular}

Table 8. Slopes composed of fracture rock with thickness of $10 \mathrm{~m}$.

\begin{tabular}{lrrrrrrr}
\hline Landslide & $c^{\prime}(\mathrm{Mpa})$ & $\alpha\left(^{\circ}\right)$ & $\varphi^{\prime}\left({ }^{\circ}\right)$ & $t(\mathrm{~m})$ & $\lambda\left(\mathrm{kN} \mathrm{m}^{-3}\right)$ & Fs & $a_{\mathrm{c}}(\mathrm{gal})$ \\
\hline Niujuangou & 0.25 & 40 & 40 & 10 & 30.0 & 2.296 & 816.667 \\
Daguangbao & 0.22 & 45 & 35 & 10 & 27.0 & 1.853 & 590.772 \\
Wangjiayan & 0.15 & 37 & 25 & 10 & 25.0 & 1.616 & 363.183 \\
Donghekou & 0.15 & 40 & 25 & 10 & 24.0 & 1.528 & 332.636 \\
\hline $1 g=980$ gal. & & & & & & &
\end{tabular}

when comparing outcomes under various slope conditions: first, it is seen that with the increasing of the slope thickness, the critical acceleration $a_{\mathrm{c}}$ is reduced, then it seems that deeper landslides are less stable than shallower landslides given the same strength values and slope angles; secondly, rock materials are important for slope stability, the harder the rock, the more stable the slopes. This agrees with our normal knowledge of slope stability; thirdly, it needs very big PGA to generate large landslides under natural conditions when the slope material is composed of coherent rock material.

After combining our calculation results of critical acceleration $a_{\mathrm{c}}$ with seismic records obtained during the Wenchuan earthquake, the calculated value of $a_{\mathrm{c}}$ in Table 8 seems realistic. Comparing the recorded peak ground accelerations at the epicenter region $(957.7,652.9$, and 948.1 gal in the EW, NS, and vertical directions, respectively) with the estimated $a_{\mathrm{c}}$ values of $408 \mathrm{gal}$ (for slope thickness $20 \mathrm{~m}$ ) and $817 \mathrm{gal}$ (for slope thickness $10 \mathrm{~m}$ ), it is found that the real ground motion is strong enough to fail the slope composed of fracture rocks with a thickness either of $10 \mathrm{~m}$ or $20 \mathrm{~m}$, but not the coherent rock material. From its initialised calculating conditions, it can be concluded that most of the very large landslides may be occurring on pre-existing fractures or discontinuity planes that were undetectable prior to the earthquake, and in this case, it seems that bigger peak ground acceleration is needed to generate large landslides in epicenter region than in the northeast terminal region because of the hard rock mass at the epicenter region.

\section{Conclusions}

The Wenchuan earthquake triggered numerous landslides, and among them many large scale landslides are responsible for the majority and tragic fatalities related to single landslides. Taking it as a special kind of landslides, our study analysed their distribution characteristics and suggests this kind of large and deep slope failures could be specifically tied to some particular geologic settings. This is in agreement with what is found in Chi-Chi earthquake (Khazai and Sitar, 2003).

1. The large landslides are dominantly developed in a narrow belt along the LSFZ, its numbers drop more rapidly with the increasing of the distance from the seismic faults when compared with other normal landslides. More than $80 \%$ of the large landslides are presented within a $5 \mathrm{~km}$ distance from the ground surface rupture;

2. Most of large landslides occurred in the region with seismic intensity higher than X except of several events occurred in IX in Qingchuan region, the northeast end of the surface rupture. This means that large landslides have a closer relationship with geological locations than ordinary landslides. The calculation of critical accelerations in different segments suggests that large landslides may have occurred on pre-existing fractures or discontinuities that were undetectable prior to the earthquake and be composed of fracture rocks. For the same scale, a greater PGA is needed to trigger large landslides when the slope is in a region covered with hard rocks;

3. The physical concentration distributions of large landslides are in good accordance with coseismic displacements measured in the field, the bigger the coseismic displacements appear, the heavier the landslides that occur. Taking account of the fact that the components of coseismic displacement value can reflect the changes of fault type and fault geometry, it can be concluded that fault type and geometry are important factors influencing the occurrence of large landslides and its concentrations. Thus, we are given the hope of predicting the 


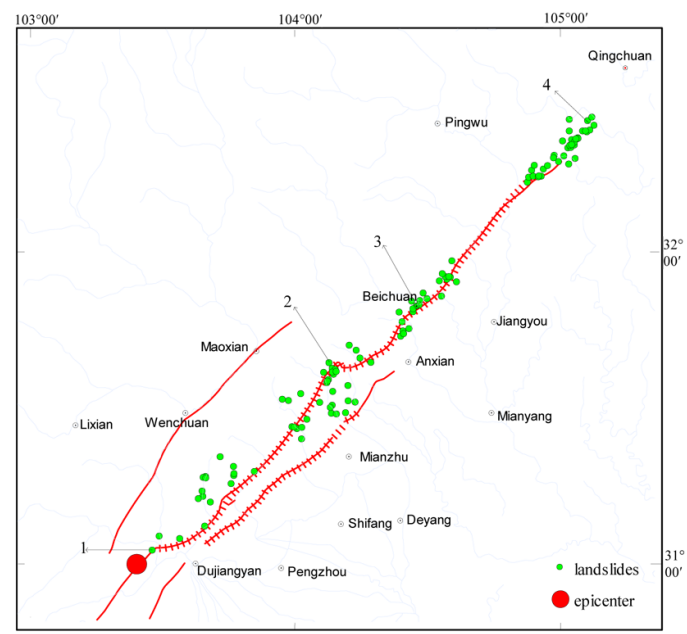

(a)

(1) Niujuangou landslide; (2) Daguangbao landslide; (3) Wangjiayan landslide; (4) Donghekou landslide

(1)
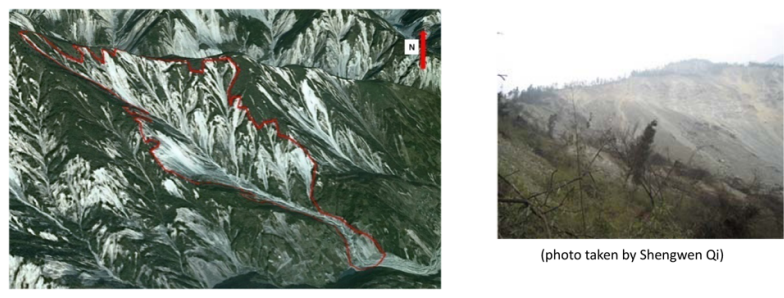

(photo taken by Shengwen oil

(2)

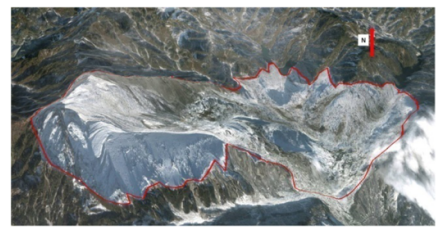

(3)
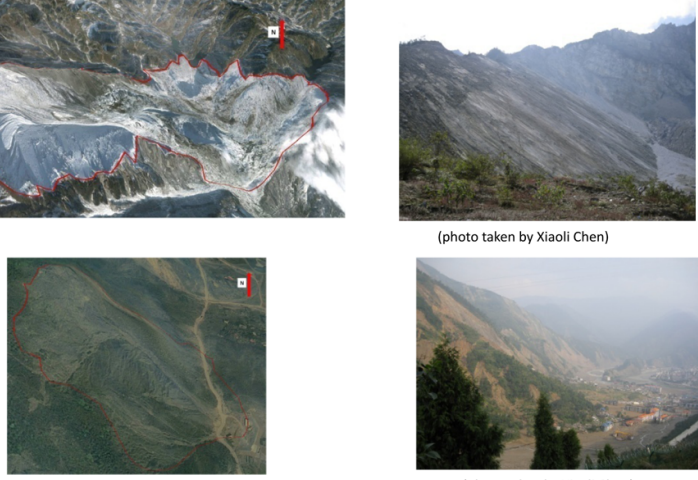

(photo taken by Xiaoli Chen)

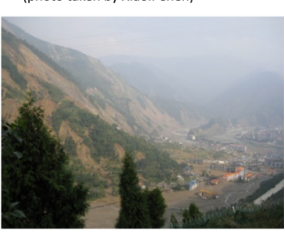

(photo taken by Xiaoli Chen)

(4)

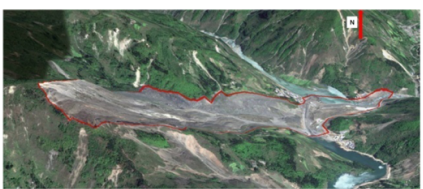

(b)

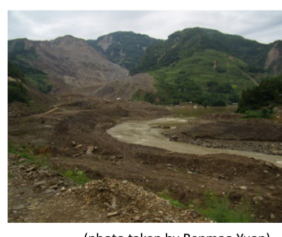

(c)

Fig. 11. Locations of the four large landslides (a) and their images (b) and photos (c). potential area of the large landslides when doing seismic hazard assessment, if fault geometry could be determined in advance.

4. From southwest to northeast, fault type changing from reverse dominated to dextral, the furthest distance between the large landslides to the rupture decreases. This suggests that reverse fault could cause large landslides in a wider region than a strike-slip fault.

Acknowledgements. This research was supported by the Institute of Geology, China Earthquake Administration (Grant No. IGCEA1006) and Ministry of Industry and Information Technology of People's Republic of China (Grant No. 2010ZX03006007). The authors would like to express deeply thanks to the anonymous reviewers and editor for thoughtful and constructive comments as well as linguistically help, which greatly improved the quality of the manuscript.

Edited by: S. Segoni

Reviewed by: R. A. Azzam and one anonymous referee

\section{References}

Abrahamson, N. and Somerville, P.: Effects of the hanging wall and footwall on ground motions recorded during the Northridge earthquake, B. Seismol. Soc. Am., 86, 93-99, 1996.

Bommer, J. J., Carlos, E., and Rodríguez, C. R.: Earthquakeinduced landslides in Central America, Eng. Geol., 63, 189-220, 2002.

Chen, X. L., Zhou, B. G., Ran, H. L., Yamamoto, Y., and Hyodo, M.: Geohazards induced by theWenchuan Earthquake, Geologically Active, Taylor \& Francis Group, London, ISBN 978-0-41560034-7, 2010.

Chen, X. L., Zhou, Q., Ran, H., and Dong, R.: Earthquake-triggered landslides in southwest China, Nat. Hazards Earth Syst. Sci., 12, 351-363, doi:10.5194/nhess-12-351-2012, 2012.

Dai, F. C., Xu, C., Yao, X., Xu, L., Tu, X. B., and Gong, Q. M.: Spatial distribution of landslides triggered by the $2008 \mathrm{Ms} 8.0$ Wenchuan earthquake, China, J. Asian Earth Sci., 40, 883-895, 2011.

Densmore, A., Ellis, A., Li, Y., Zhou, R. J., Hancock, G. S., and Richardson, N.: Active tectonics of the Beichuan and Pengguan faults at the eastern margin of the Tibetan Plateau, Tectonics, 26, 1-17, 2007.

General Administration of Quality Supervision, Inspection and Quarantine of the peolple's Republic of China, Ministry of construction of the People's Republic of China: Standard for engineering classification of rock masses, Beijing, Standards Press of China, 1995 (in Chinese).

Guzzetti, F., Carrara, A., Cardinali, M., and Reichenbach, P.: Landslide hazard evaluation: a review of current techniques and their application in a multi-scale study, Central Italy, Geomorphology, 31, 181-216, 1999.

Haeussler, P. J., Schwartz, D. P., Dawson, T. E., Stenner, H. D., Lienkaemper, J. J., Sherrod, B., Cinti, F. R., Montone, P., Craw, P. A., Crone, A. J., and Personius, S. F.: Surface Rupture and 
Slip Distribution of the Denali and Totschunda Faults in the 3 November 2002 M 7.9 Earthquake, B. Seismol. Soc. Am., 94, 23-52, 2004.

Harp, E. L. and Jibson, R. W.: Landslides triggered by the 1994 Northridge, California earthquake, B. Seismol. Soc. Am., 86, s319-s332, 1996.

Harp, E. L., Wilson, R. C., and Wieczorek, G. F.: Landslides from the February 4, 1976, Guatemala earthquake, US, Geological Survey Professional Paper, 1204A, 1981.

Hsü, K. J.: Catastrophic debris streams (sturzstroms) generated by rockfalls, Bull. Geol. Soc. Am., 86, 129-140, 1975.

Huang, R. Q. and Li, W. L.: A study on the development and distribution rules of geohazards triggered by " 5.12 " Wenchuan Earthquake, Chinese J. Rock Mech. Eng., 27, 2585-2592, 2008 (in Chinese).

Huang, R. Q., Pei, X. J., Zhang, W. F., Li, S. G., and Li, B. L.: Further examination on characteristics and formation mechanism of Daguangbao landslide, J. Eng. Geol., 17, 725-736, 2010 (in Chinese).

Jibson, R. W. and Michael, J. A.: Maps Showing Seismic Landslide Hazards in Anchorage, Alaska, US Geological Survey, available at: http://pubs.usgs.gov/sim/3077/, 2010.

Jibson, R. W., Harp, E. L., and, Michael, J. A.: A method for producing digital probabilistic seismic landslide, Eng. Geol., 58, 271-289, 2000.

Jibson, R. W., Harp, E. L., Schulz, W., and Keefer, D. K.: Landslides triggered by the 2002 M-7.9 Denali Fault, Alaska, earthquake and the inferred nature of the strong shaking, Earthquake Spectra, 20, 669-691, 2004.

Keefer D. K.: Landslides caused by earthquakes, Geol. Soc. Am. Bull., 95, 406-421, 1984.

Keefer, D. K.: Statistical analysis of an earthquake-induced landslide distribution - the 1989 Loma Prieta, California event, Eng. Geol., 58, 231-249, 2000.

Keefer, D. K.: Investigating landslides caused by earthquakes - a historical review, Surv. Geophys., 23, 473-510, 2002.

Khazai, B. and Sitar, N.: Evaluation of factors controlling earthquake-induced landslides caused by Chi-Chi earthquake and comparison with the Northridge and Loma Prieta events, Eng. Geol., 71, 79-95, 2003.

Kieffer, D. S., Jibson, R., Rathje, E. M., and Keith Kelson, K.: Landslides Triggered by the 2004 Niigata Ken Chuetsu, Japan, Earthquake, Earthquake Spectra, 22, S47-S73, 2006.

Li, X. J., Zhou, Z. H., Huang, M., Wen, R. Z., Yu, H. Y., Lu, D. W., Zhou, Y. N., and Cui, J. W.: Preliminary Analysis of StrongMotion Recordings from the Magnitude 8.0 Wenchuan, China, Earthquake of 12 May 2008, Seismol. Res. Lett., 79, 844-854, 2008.

Meunier, P., Hovius, N., and Haines, J. A.: Regional patterns of earthquake-triggered landslides and their relation to ground motion, Geophys. Res. Lett., 34, L20408, doi:10.1029/2007GL031337, 2007.

National Wenchuan Earthquake experts committee: Atlas of seismic hazard during Wenchuan Earthquake, Beijing, SinoMaps Press, 2008 (in Chinese).

Oglesby, D. D. and Day, S. M.: Fault geometry and the dynamics of the 1999 Chi-Chi (Taiwan) Earthquake, Bull. Seismol. Soc. Am., 91, 1099-1111, 2001.
Qi, S. W., Xu, Q., Lan, H. X., Zhang, B., and Liu, J. Y.: Spatial distribution analysis of landslides triggered by 2008.5.12 Wenchuan Earthquake, China, Eng. Geol., 116, 95-108, 2010.

Qi, S. W., Xu, Q., Zhang, B., Zhou, Y. D., Lan, H. X., and Li, L. H.: Source characteristics of long runout rock avalanches triggered by the 2008 Wenchuan earthquake, China, J. Asian Earth Sci., 40, 896-906, 2011.

Qiao, J. P. and $\mathrm{Pu}, \mathrm{X}$. H.: A preliminary study on the distributive regulation of seismic landslide in Sichuan and Yunnan, J. Seismol. Res., 15, 411-417, 1992 (in Chinese).

Rodríguez, C. E., Bommerb, J. J., and Chandlerb, R. J.: Earthquakeinduced landslides: 1980-1997, Soil Dynam. Earthq. Eng., 18, 325-346, 1999.

Sassa, K., Fukuoka, H., and Wang, F. W.: Dynamic properties of earthquake-induced large-scale rapid landslides within past landslide masses, Landslides, 2, 125-134, 2005.

Scott, S. B. and Keefer, D. K.: Seismic landslide hazard for the city of Berkeley, California, USGS, Open file, 2001.

Shen, Z. K., Sun, J. B., Zhang, P. Z., Wan, Y. G., Wang, M., Bürgmann, R., Zeng, Y. H., Gan, W. J., Liao, H., and Wang, Q. L.: Slip maxima at fault junctions and rupturing of barriers during the 2008 Wenchuan earthquake, Nat. Geosci., 2, online first, doi:10.1038/NGEO636, 2009.

Simonett, D. S.: Landslide distribution and earthquakes in the Bewani and Torricelli Mountains, New Guinea, statistical analysis, in Landform Studies from Australia and New Guinea, edited by: Jennings, J. N. and Mabbutt, J. A., Cambridge, Cambridge University Press, 64-84, 1967.

Wang, H. B., Sassa, K., and Xu, W. Y.: Analysis of a spatial distribution of landslides triggered by the 2004 Chuetsu earthquakes of Niigata Prefecture, Japan, Nat. Hazards, 41, 43-60, 2007.

Wang, W. N., Wu, H. L., Nakamura, H., Wu, S. C., Ouyang, S., and Yu, M. F.: Mass movements caused by recent tectonic activity: The 1999 Chi-chi earthquake in central Taiwan, The Island Arc, 12,325-334, 2003.

Wang, Y. S., Luo, Y. H., Ji, F., Huo, J. J.,Wu, J. F., and Xu, H. B.: Analysis of the controlling factors on geo-hazards in mountainous epicentre zones of the Wenchuan Earthquake, J. Eng. Geol., 16, 759-763, 2008 (in Chinese).

Wen, B. P., Wang, S. J., Wang, E. Z., and Zhang, J. M.: Characteristics of rapid giant landslides in China, Landslides, 4, 247-261, 2004.

Wilson, R. C. and Keefer, D. K.: Predicting areal limits of earthquake-induced landsliding, In evaluating earthquake hazards in Los Angeles region, US Geological Survey, Professional Paper 1360, 317-345, 1985.

Wu, S. R., Wang, T., Shi, L., Sun, P., Shi, J. S., Li, B., Xin, P., and Wang, H. B.: Study on catastrophic landslides triggered by 2008 Great Wenhcuan Earthquake, Sichuan, China, J. Eng. Geol., 18, 145-159, 2010 (in Chinese).

Xu, Q. and Li, W. L.: Distribution of large scale landslides induced by the Wenchuan earthquake, J. Eng. Geol., 18, 818-826, 2010 (in Chinese).

Xu, X. W., Wen, X. Z., Yu, G. H., Chen, G. H., Klinger, Y., Hubbard, J., and Shaw, J.: Coseismic reverse- and oblique-slip surface faulting generated by the 2008 Mw7.9 Wenchuan earthquake, China, Geology, 37, 515-518, doi:L10.1130/G25462A, 2009. 
Yang, T., Deng, R. G., and Liu, X. L.: The distributing and subarea character of the seismic landslides in Sichuan, J. Mountain Sci., 20, 456-460, 2002 (in Chinese).

Yin, Y. P.: Rapid and long run-out features of landslides triggered by the Wenchuan Earthquake, J. Eng. Geol., 17, 153-166, 2009 (in Chinese).

Yin, Y. P., Wang, F. W., and Sun, P.: Landslide hazards triggered by the 2008 Wenchuan earthquake, Sichuan, China, Landslides, 6 , 139-152, 2009.

Yu, G. H., Xu, X. W., Klinger, Y., Diao, G. L., Chen, G. H., Feng, X. D., Li, C. X., Zhu, A. L., Yuan, R. M., Guo, T. T., Sun, X. Z., Tan, X. B., and An, Y. F.: 2010. Fault-Scarp Features and CascadingRupture Model for the Mw 7.9 Wenchuan Earthquake, Eastern Tibetan Plateau, China, B. Seismol. Soc. Am., 100, 2590-2614, doi:10.1785/0120090255, 2010.

Yuan, R. M., Xu, X. W., Chen, G. H., Tan, X. B., Klinger, Y., and Xing, H. L.: Ejection landslide at northern terminus of Beichuan rupture triggered by the $2008 \mathrm{M}_{w} 7.9$ Wenchuan earthquake, B. Seismol. Soc. Am., 100, 2689-2699, doi:10.1785/0120090256, 2010 .
Zhang, P. Z., Wen, X. Z., Xu, X. W., Gan, W. J., Wang, M., Shen, Z. K., Wang, Q. L., Huang, Y., Zheng, Y., Li, X. J., Zhang, Z. Q., Ma, S. L., Ran, Y. K., Liu, Q. Y., Ding, Z. F., and Wu, J. P.: Tectonic model of the great Wenchuan earthquake of May 12, 2008, Sichuan, China, Chinese Sci. Bull, 54, 944-953, 2009 (in Chinese).

Zhao, C. P., Chen, Z. L., Zhou, L. Q., Li, Z. X., and Kang, Y.: Rupture process of the Wenchuan M8.0 earthquake of Sichuan, China: the segmentation feature, Chinese Sci. Bull., 55, 284-292, 2010 (in Chinese).

Zhu, A. L., Xu, X. W., Diao, G. L., Su, J. R., Feng, X. D., Sun, Q., and Wang, Y. L.: Relocation of the Ms 8.0 Wenchuan Earthquake sequence in part: preliminary seismotectonic analysis, Seismol. Geol., 30, 759-767, 2008 (in Chinese). 